IRA-International Journal of Education \& Multidisciplinary Studies

ISSN 2455-2526; Vol.11, Issue 01 (April, 2018)

Pg. no. 1-12.

Institute of Research Advances

http://research-advances.org/index.php/IJEMS

\title{
Education System in Ethiopia and India: Comparative Analysis of Selected Educational Issues
}

\author{
Tariku Sime $^{1 \#}$, Gara Latchanna ${ }^{2}$ \\ ${ }^{1}$ Department of TECS, Jimma University, Ethiopia. \\ ${ }^{2}$ Department of Education, Andhra University, India..
}

\# corresponding author.

Type of Review: Peer Reviewed.

DOI: http://dx.doi.org/10.21013/jems.v11.n1.p1

\section{How to cite this paper:}

Sime, T., Latchanna, G. (2018). Education System in Ethiopia and India: Comparative Analysis of Selected Educational Issues. IRA International Journal of Education and Multidisciplinary Studies (ISSN 2455-2526), 11(1), 1-12.doi: http://dx.doi.org/10.21013/jems.v11.n1.p1

(C) Institute of Research Advances.

\section{(cc)) BY-NC}

This work is licensed under a Creative Commons Attribution-Non Commercial 4.0 International License subject to proper citation to the publication source of the work.

Disclaimer: The scholarly papers as reviewed and published by the Institute of Research Advances (IRA) are the views and opinions of their respective authors and are not the views or opinions of the IRA. The IRA disclaims of any harm or loss caused due to the published content to any party.

Institute of Research Advances is an institutional publisher member of Publishers Inter Linking Association Inc. (PILA-CrossRef), USA. The institute is an institutional signatory to the Budapest Open Access Initiative, Hungary advocating the open access of scientific and scholarly knowledge. The Institute is a registered content provider under Open Access Initiative Protocol for Metadata Harvesting (OAI-PMH).

The journal is indexed \& included in WorldCat Discovery Service (USA), CrossRef Metadata Search (USA), WorldCat (USA), OCLC (USA), Open J-Gate (India), EZB (Germany) Scilit (Switzerland), Airiti (China), Bielefeld Academic Search Engine (BASE) of Bielefeld University, Germany, PKP Index of Simon Fraser University, Canada. 


\begin{abstract}
In the era of globalization, nations invest in their education system to be the best so that their children can fit to the order of the day through acquiring and developing the necessary skills, knowledge, values and dispositions. The institutions meant to provide these services: schools, colleges/universities, based on the education policy, play indispensable role to face the challenges of contemporary society especially in the $21^{\text {st }}$ century. The article explored how Ethiopian and Indian education systems are similar and different based on the major unit of analysis viz. historical development, education and training policy, structure of the education system, teacher quality and teaching environment, and governance and financing in education. In other words, it dealt with issues where both countries differ and how they are leading the student's progression from their pre-primary to terminal degree programs with far-reaching recommendations to augment the value of education.
\end{abstract}

Key Word(s): Education system, comparative analysis, educational issues

\title{
INTRODUCTION
}

Erasmus once said, "The main hope of a nation lies in the proper education of its youth."(Alao, 2013).Even if the great philosophers and thinkers, from the dawn of human history through different periods of civilisation, have attempted to explicate, the purpose of education has always been to everyone, in essence, the same-to equip the young with the knowledge, skills and values they need in order to cope up and develop in an orderly, sequential way into members of society. This is the purpose of education entrusted to youths of affluent or developing nations, whether it goes on in a one-room school in the remote village or in the most advanced, progressive school in a dynamic community. The intensity of the purpose, however, has been under a change in the evolution of socioeconomic development. For instance, recently it has been changed from that of producing a literate society to that of creating a learning society. Here, in this study, it is intended to analyse the education system of two historically, geographically, economically, demographically and socially distinct nations: Ethiopia and India. Both nations run education system within their own diversity dimensions of religion, ethnicity, language, socioeconomic background and whatever other differences counted. However, they are similar in being a nation of mosaic society. Moreover, these nations are one of the top emerging economies in their region; East Africa and South-central Asia respectively(UNECA,2011;Claire,2013;Persis,2013). Education, nevertheless, as an instrument of change has been institutionalized in different era, although any education is, in its forms and methods, an outgrowth of the needs of the society in which it exists. This is what inspired us, the authors, to investigate their similarities and differences along with common elements of essential educational issues. Even if the parameters for comparative analysis are different and diverse, the study is delimited to major educational issues related with development, education policy, structure, teacher education and financing education.

\section{OBJECTIVES OF THE STUDY}

Taking in to account the fundamental educational issues selected for the analysis, the study is meant to:

- Highlight the education system in Ethiopia and India;

- Draw a comparison between the two systems so as to understand the merits and flaws of each;

- Show implications so that the countries would pave the way for future considerations.

\section{SIGNIFICANCE OF THE STUDY}

Regarding its benefits, results of the study might ignite interest in other researchers to deal in detail with the issue using this study as spring board. Moreover, practitioners at educational institutions of the two countries may get easy access to the overview of the most important issues in the system. It may also serve people who have in touch with policy developments to figure out essential elements to be treated in the document.

\section{METHOD}

This study is a comparative educational research primarily examining educational phenomena in different places. The study employed secondary sources of data, viz. journals, periodicals and government publications for the comparative analysis based on Bereday's (1964) adopted model consisting of four steps: description, interpretation, juxtaposition and simultaneous comparison. A prerequisite for any comparative study is to establish the parameters for initial comparability of the chosen units of analysis (Manzon, 2007). Accordingly, the major educational issues of each country i.e. brief historical development, education policy, structure of education system, teacher education and learning environment and governance and financing education sector are taken as unit of analysis and addressed separately. Finally, their differences and similarities are cautiously identified and discussed. 


\section{ETHIOPIAN EDUCATION SYSTEM}

For better understanding of the fundamental educational issues, the paper begins with the brief historical overview of education system in the country and winds up with how education sector is being financed.

\section{History of Education in Ethiopia}

Located in the Horn of Africa, Ethiopia is one of the oldest nations in the world. It is accredited as being the origin of mankind and is the second most populous country in Sub-Saharan Africa after Nigeria. Unlike most other African countries, Ethiopia did not experience momentous colonization; except for a brief Italian occupation from 1936 to 1941(Herbst, 2000).

Two major traditions characterize the development of education in Ethiopia:"traditional" and "Western/modern" systems. While Western educational ideas have flourished since the early twentieth century, the traditional education was predominant throughout the history of the ancient nation in the form of indigenous and religious education. Even if the country experienced myriads of challenges and opportunities throughout its history, we would like to fix our analyses only on modern education. To make the overview self reflective, we present based on the historical governing bodies (regimes) of the nation.

The first modern school was opened in 1908 with the objective of educating the young to ensure peace and reconstructing the country, and enabling Ethiopia to exist as a great nation (Pankhurst, 1976). It was also aimed at producing administrators, interpreters and technicians to build sustainable external relations capacity specifically with the western countries (Teshome, 1979).

Till the Italian occupation (1936), the major purpose of education was limited to mastering different languages (especially Foreign). As a result, the curriculum was mostly composed of such language courses as French, Italian, Geez, Arabic and Amharic. Additionally, some courses in religion, mathematics, law and calligraphy were offered (Adane, 1996). During this time, the Ethiopian education system and its curricular components (objectives of education, contents or courses to be taught, organization of a school and its management, and the method of evaluation) were principally influenced by the French education system. The selection and organization of content were determined by the headmasters and teachers from France, and French was used in Ethiopia as medium of instruction. All important resources were from abroad except students.

Italian occupation brought down totally the creeping education system through strategies of persecution of the elites and changing educational institutions into military camps. Moreover, catholic mission schools were mandated to emphasize religion and Italian language to subordinate people to the Mussolini regime. In general, the major goal of education was to create citizens that would be loyal to Italy. The content of education focused mainly on basic skills (restricted to grade 4) and semi-vocational skill training and internalizing fascist values to promote fidelity to the regime. Furthermore, mother tongue was taken as a medium of instruction for major ethnic groups even if (as many agree) the purpose was not pedagogical (Adane, 1996).The curricula and assessment, during this time, were neither uniform nor standardized in the schools.

The next turn was Great Britain's domination from 1942-1954 where the support in liberating Ethiopia from Italian aggression was taken as a pretext to manipulate the education system of the country. During this time, the system was highly influenced by British advisors not only at policy level but also in schools and classroom contexts(Zewudie, 2000).Like the French domination time, every aspect was from abroad except the students and the trend depicts the irrelevance of the curriculum across all regimes once again. The need of the society and what was going on in the school didn't match and it became only the political agenda of the aristocracy and their overseas advisors.

After 1953, reforms regarding the involvement and participation of educated Ethiopians were put in place. Human resource development was given due attention in this period, which led to the involvement of Ethiopians in areas ranging from policy making to classroom practice. Gradually, the role of Britain decreased and USA began to take over the position and highly influenced till 1965 and continued until 1971 Education Sector Review long term plan preparation. Later on the government began to realize the importance of Ethiopian placement and contribution in the system through various capacity building strategies though political in essence. There were two major changes during American time. The structure of the school changed to $6+2+4$ and Amharic was promoted to medium of instruction at primary school level (Tekeste, 1990).

The Derg, military Regime, came to power in 1974, chanting socialism as the cardinal political philosophy and slogan of the government. Marxist-Leninist philosophy overwhelmed and guided the overall aspect of the country. It is said to be there had been no other time in the Ethiopian history that education was used as a vital 
tool to maintain political power (Tekeste, 1990). The prime purpose of education at all levels targeted at propagating the then Eastern bloc ideology leaving aside the reality on the ground. This view was articulated through various important documents such as National Democratic Revolution in 1976, General Directives of Ethiopian Education in 1980, and the guidelines of the Working Party of Ethiopia in 1984.

After the current government came to power following the downfall of the military government in 1991, the education policy was changed which resulted in dramatic progress in enrolment from 2.8 million, for example, in primary education (grades 1-8) in 1990/91 to 18 million in 2013/14(MoE, 2014). Nonetheless, the way to progress was not an easy task for the country has been in deep rooted and complex multifaceted challenges in all sectors. Despite the encouraging results, there are numerous problems putting in to question the quality of education sector currently. In addition, globalization and demographic changes have exacerbated the situation resulting in abysmal education standard even at sub-Saharan African region.

\section{Education and Training Policy}

Although modern education was introduced to Ethiopia a century ago, the education and training offered during these long years hardly changed the lives of the people and contributed to national development. The basic longstanding problems related to the Ethiopian education system were fundamentally limited and inequitable access, lack of quality and relevance, and continuous decline the quality and standard (MoE, 2002).

To curb these challenges, the current government developed education and training policy targeting the cultivation of citizens with an all-round education capable of playing conscious and active role in the economic, social, and political life of the country at various levels (TGE, 1994). To achieve the goal, it is vital to ascertain the cardinal problems of the educational system are gradually being dissolved. To this effort, various strategies and methods have been devised to rectify the problems identified. Eventually, the following objectives were addressed as leading purposes of the education system in the country.

The major objectives are set to:

- Develop the physical and mental potential and the problem-solving capacity of individuals by expanding education and in particular by providing basic education for all.

- $\quad$ Bring up citizens who can take care of and utilize resources wisely, who are trained in various skills, by raising the private and social benefits of education.

- Bring up citizens who respect human rights, stand for the well-being of people, as well as for equality, justice and peace, endowed with democratic culture and discipline.

- Bring up citizen who differentiate harmful practices from useful ones, who seek and stand for truth, appreciate aesthetics and show positive attitude towards the development and dissemination of science and technology in society.

- Cultivate the cognitive, creative, productive and appreciative potential of citizens by appropriately relating education to environmental and societal needs.

After the implementation, there have been questions, doubts and reservations from different stakeholders on medium of instruction at different levels of education, the self-contained class-room management and continuous assessment, especially at the first cycle primary level, placement of students in higher education, "Free" education for all and the comparison of basic differences between the present education and training policy with the previous policies and strategies.

\section{Structure of Education in Ethiopia}

The educational reforms put into effect in 1994 changed the old structure of the system which was working since 1962.General education was categorized into Pre primary( to children aged four to six, primary( Grades16),junior secondary(Grade $7 \& 8$ ) and senior secondary ( Grades 9-12) with national examination at the end of each level. Education Statistics annual abstract of Ministry of Education(2013) shows the current education system has eight years of primary education consisting of two cycles; primary first cycle (Grades 1-4) meant for basic functional literacy and primary second cycle (Grades 5-8) which is a preparation stage for further education. It is followed by general secondary education (Grades 9\&10) and upper secondary/preparatory education (Grades 11\&12).

The system is framed to help students to graduate the formal school system with higher levels of literacy and numeracy and with options for pursuing technical and vocational training at various levels of the education system. The general secondary education (Grades 9 and 10) is aimed at enabling learners to identify areas of interest for future training and world of work. The upper secondary school (Grades 11 and 12) is meant to prepare students for continuing their studies at the higher learning institutions or choosing their own vocations. 
Technical and vocational education and training is structurally different from the regular education system however runs in parallel with it. There is training at the exit points of the academic levels (rades 4, 8 and 10).Even if the difference is clear across different levels and years, the following table taken from annual abstract(2013/14) of Ministry of Education portrays growth in the number of institutions and schools in the country.

\begin{tabular}{lcccccc}
\hline \multicolumn{1}{c}{ Year } & $\mathbf{2 0 0 9 / 1 0}$ & $\mathbf{2 0 1 0 / 1 1}$ & $\mathbf{2 0 1 1 / 1 2}$ & $\mathbf{2 0 1 2 / 1 3}$ & $\mathbf{2 0 1 3 / 1 4}$ & $\begin{array}{c}\text { Average growth } \\
\text { rchool }\end{array}$ \\
\cline { 1 - 5 } Kindergarten & 3318 & 3418 & 3580 & 3688 & 4560 & 6.6 \\
Primary & 26951 & 28349 & 29643 & 30495 & 32048 & 3.5 \\
Secondary & 1335 & 1517 & 1710 & 1912 & 2333 & 11.8 \\
Teacher education & 29 & 32 & 32 & 34 & 34 & 3.2 \\
TVET & 460 & 505 & 505 & 437 & 1350 & 24.0 \\
Higher Education & 70 & 74 & 91 & 99 & 124 & 12.1 \\
Total & 32163 & 33895 & 35561 & 3665 & 40449 & 4.7 \\
\hline
\end{tabular}

Table 1: School and institutions, growth at different structural levels

Higher education is run by mandated institutes, colleges and universities. Post-secondary non-university vocational and technical education programmes are entertained by colleges and technological institutes leading to the award of a diploma after they pass through different phases. Primary Teacher Training Institutes certify candidates with one-year courses preparing for teaching in basic education. A diploma awarded by Teacher Training Colleges is mandatory to teach in general education. Secondary school teachers expected to have at least a first degree. At the university level, programmes leading to first degree take three to four years to complete (five years in the case of law and pharmacy; six years in the case of medicine and veterinary science). At the postgraduate level, master's degree programmes last at minimum for two years; a specialization programmes with diploma takes between three and four years. It lasts usually three (with variations ranging from four to five) years to graduate with terminal degree. The above descriptions are demonstrated by the following pictorial representation (Figure 1) of each level in the Education Statistics Annual Abstract published by Ministry of Education (2013/14).

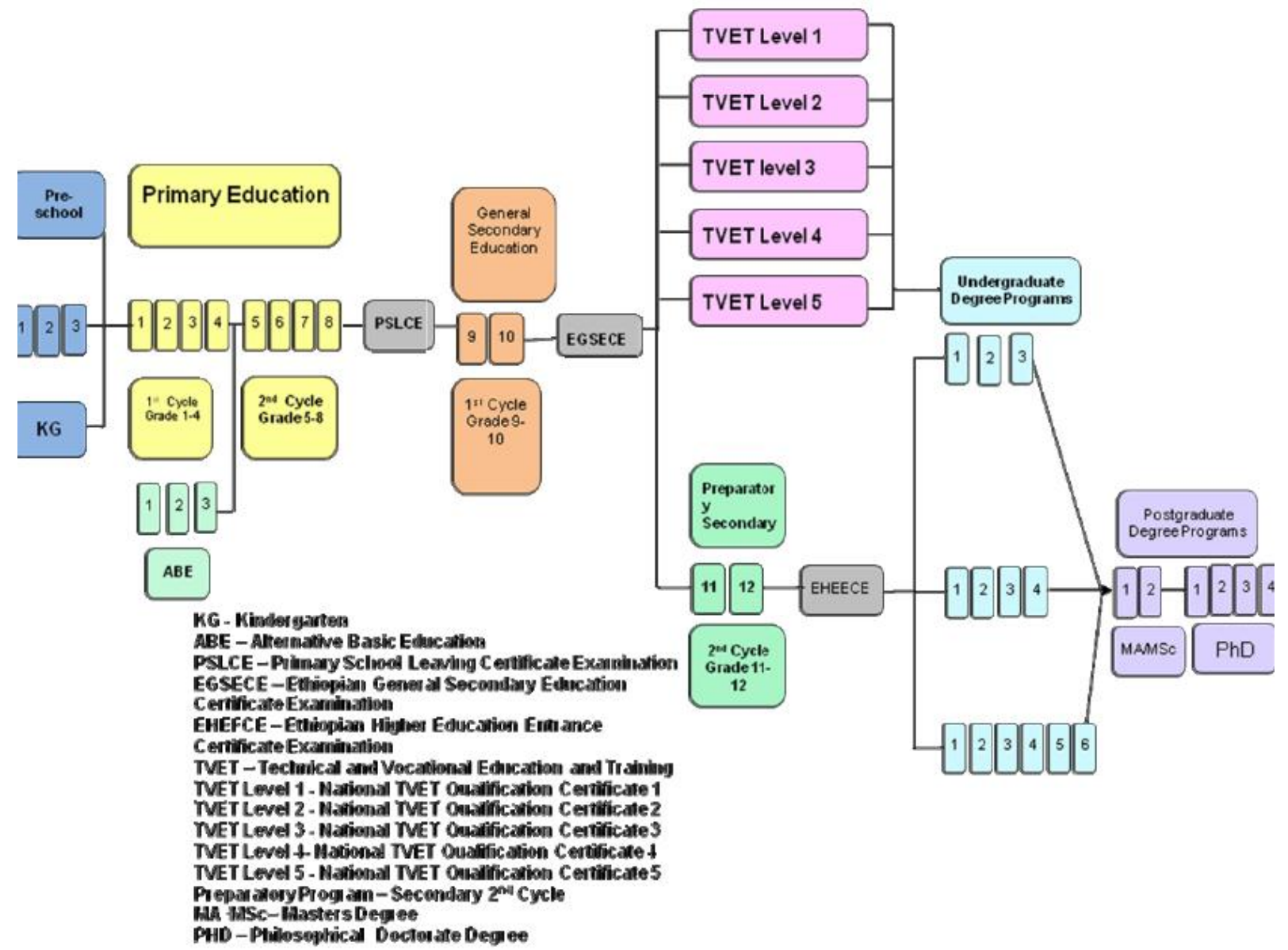

Figure 1: Structure of the Ethiopian Education System 


\section{Teacher Quality and Teaching Environment}

Quality of teachers and their availability in addition to School leaders, school facilities (resources, financial, material and human) and supervisors are among the essential tenets of quality education at all levels .It is difficult to measure teacher quality for they are expected to manifest qualities beyond countable criteria. However, core overt features such as qualifications, training, specialization, experience etc can be taken as preferable proxies for quality (Rockoff, 2004).

The issues of education quality in general and teacher training and development programmes in particular have remained a huge challenge for the Ethiopian education system for many years (Workineh and Tassew, 2013).However, since the current government came to power, new education and training policy was formulated so as it contributes a lot to the development of the country and then to reduce poverty. To bring the desired effect, the Government has committed itself to train teachers through both pre-service and in-service training programmes, though shortages continue to exist because of mismatch between number of schools and teachers as new schools are founded at kebele level.

Cognizant of the importance of teacher training for quality education, the government considers accelerated teacher training and development programmes to be a means of ensuring quality education. The first Education Sector Development Programme (ESDP I) figured out the shortage of qualified teachers as one of the major pulling factors to compromising quality of education. Report from $\operatorname{MoE}(1998)$ reveals that by the beginning of the 1990s only 40 per cent of the teachers teaching at Grades 9-12 were 1st degree holders, the minimum qualification for teaching at this level. As a result ESDP (Education Sector Development Programme) I, afterwards ESDP, was designed to implement the major policy reforms outlined in the 1994 Education and Training Policy. In line with this, the major objective of ESDP I was to improve teacher training programmes. In ESDP II, teacher training issues were further strengthened in the target of providing equitable access to education. The subsequent programmes, ESDP III and IV, articulate in crystal clear about standardization of teacher training programmes and employment of active learning and student centred approach in class room teaching respectively.

In 2003/4 Ethiopia introduced the new reform, Teacher Education System Overhaul (TESO) with a new curriculum promoting active learning and student-centred approaches. This curriculum was instituted in most of the teacher training learning institutions across the country (Amare et'al,2006). The intention was to replace the traditional teacher-centred approach with active learning, in which students can interact with teachers and other students (Serbessa,2006) although it was not effective as planned at the very beginning. Still there are myriads of factors that hinder the availability and quality of teachers which invites researchers to investigate in detail. For instance, the government's special concern for science and technology disciplines leaving aside social sciences and humanities has its own impact in this regard albeit it requires further research.

\section{Governance and Financing Education Sector}

The educational system has been structured in line with the Federal Government's State formation. Accordingly, each of the 9 National Regional States and the 2 City Administrations has its decentralized bureaus of education charged with administrating, financing and managing all issues pertaining to education. To come up with strong cumulative effect of the system, the network has been stretched from the smallest educational authority (Wereda education office) to the zonal (district level) education departments guided and supported by regions. It is through this structure that the system works at regional level. Federal government owned educational issues such as policy directives and higher education management are the mandate of the central government's Ministry of Education though states have great contribution in the contextual implementation of the policy and management for the institutions are in their territories. The following figure depicts the distribution of education expenditure between 2005/06 and 2009/10(MoE, 2005). 


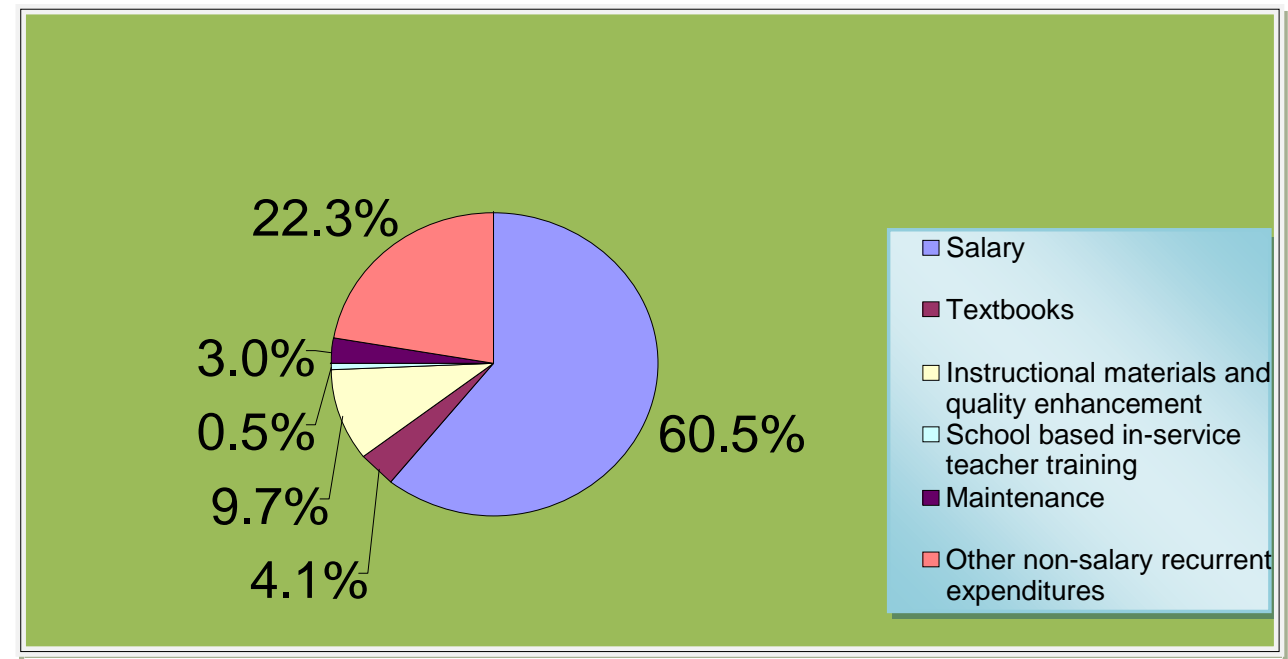

Figure 2: Distribution of Recurrent Expenditure (2005/06 - 2009/10)

\section{INDIAN EDUCATION SYSTEM}

In the previous part, the major concerns of education system in the Ethiopian context presented. With the same fashion, the Indian education system in line with the common parameters goes as follows.

\section{Brief Overview of Education Development in India}

Education and its development in India have a rich and interesting history. In this article, however, we highlight pre-independence education system and scrutinize in detail the modern aspect of education especially trends after independence. This is just to figure out the common issues to be treated in the comparative analyses of the two countries.

It is believed to be in the ancient days, the education was imparted orally by the sages of the time to pass information from generation to generation. After letters coined, however, it took the form of inscription using the palm leaves and the barks of trees. This also supported a lot in developing and spreading the written literature across the country. Gradually, the temples and the community centres began to frame the role of schools. As a result, the Gurukul system of education came into existence. The Gurukul system of education is one of the oldest on earth, and was dedicated to the highest ideals of all round human development: Mental, physical and spiritual. At the Gurukuls, the teachers imparted knowledge of Religion, Philosophy, Warefare, Medicine, Scripture, Literature, Statecraft, Astrology and history (Nick, 2006).

Education system in pre-independence India has gone through historical periods of the Upanishadic , Buddhist, medieval and the modern time. Every period has its own strengths and weaknesses. For example, in line with the beginning of modern organized education, from the Madarsa at Calcutta in 1871 to the Sergeant Report of 1944 , a number of reforms had been under way. To mention the major ones; Lord Macaulay's Minute, Wood's Dispatch on Education in 1854, The Indian Education Commission in 1882, The Indian University Act in 1904, The Government of India Resolution in 1913, The Calcutta University Commission in1917-19, The Hartog Committee of 1929, Wardha Scheme of Basic Education in 1937.

The nature of education after independence has many features like the pre-independence time. In postIndependence era; however, the purpose has been for the development of the nation not to serve the bureaucracies of the rulers. From the evolution of the educational development of the country after independence, the following indispensable summaries might be drawn:

Important institutions like NCERT (National Council of Educational Research and Training), CBSE (Central Board of Secondary Education) etc came up in order to provide framework for primary and secondary education shifting the focus to improve enrolment and literacy levels in the country. This was further strengthened with the announcement of policy of education in 1968, 1976, 1986 and 1992. To up lift the standard of higher education premier institutions like the IITs (Indian Institute of Technology) and IIMs (Indian Institute of Management) came in to being; one of world class universities today. Moreover, in 2002, education was made a fundamental right of citizens and became compulsory in 2009. 
However, it seems that there is consensus on the low quality of education at all levels of learning. That is why currently the government is working aggressively on setting platform for discussion to identify the real problems from all stakeholders to modify or change the working education policy.

\section{Education Policy}

Any education policy is crucial since it gives a direction and vision to the sector. In relation to this, India-post independence has formulated various education policies in 1968, 1986, and 1992. Extensive reflection preceded formulation of these policies. They were feasible to the then situation. For instance, India literacy rate in 1947 was $12 \%$ which rose to $74 \%$ in 2011 which shows the efforts exerted by government to revamp education since independence. However, one serious lacuna which affects India's education to this day is the poor implementation of the policies. On a practical level, as different researches reveal, the policies haven't been effective.

In 1968, when the National Policy of Education was formulated to improve the educational scenario of the country which called for a "radical restructuring" and equalise educational opportunities in order to achieve national integration and greater cultural and economic development", it was envisaged to be followed by a five yearly review to progress and working out of new policies and programmes through various strategies of identifying the empirical problems. The National Policy of Education of 1986 and 1992 are the result of this endeavour. The current policy was modified based on the National Programme of Action of 1992 report led by the then chief minister of Andhra Pradesh. This policy aimed to promote national progress, a sense of common citizenship and culture, and to strengthen national integration. It laid stress on the need for a radical reconstruction of the education system, to improve its quality at all stages, and therefore gave much greater attention to science and technology, the cultivation of moral values and a closer relation between education and the life of the people (Ranganathan,2007).

\section{Structure of Education in India}

India, being a confederation of states, has accepted a uniform pattern of school and college education commonly known as "10+2+3"structure. This structure depicts 10 years of general education; the first eight years for primary and the couple of years for secondary; then 2 years of Senior Secondary followed by 3 years of College Education leads to the award of bachelor degree. A few years ago different structures such as $8+3+3,10+1+3$, or $10+2+2$ were functional in different states. However, recommendations of the Education Commission (1964-66) and the proposals of the National Policy of Education-1968, enforced most of the states to adopt the current structure. The National Policy on Education (NPE)-1986 also strongly recommended the importance of adopting a common structure $10+2+3$, across the country. It also proposed to adopt a common structure of elementary education consisting of 8 years of schooling - 5 years of Primary and 3 years of Upper Primary education. Therefore, the present structure of school education can be represented as $\{(5+3)+2+2\}$. The following figure depicts clearly the structure of education system in the country.

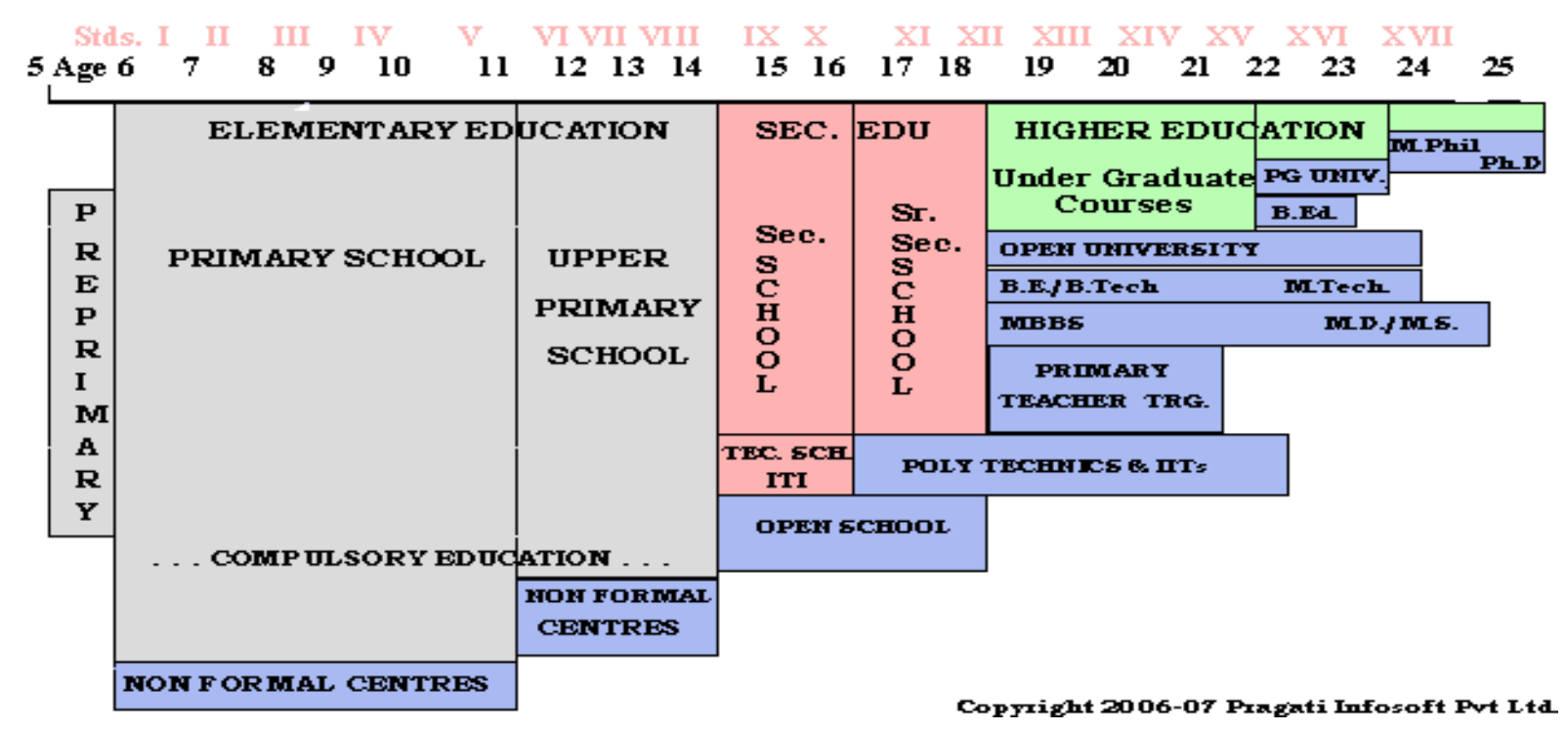

Figure 3: Structure of education system in India 
A child is admitted to class I, normally, at the age of 6 years and is supposed to complete primary education first cycle at the age of 11 , and second cycle at the age of 14 . Primary education is free as bestowed in the constitution.

Secondary education popularly known as "High School" is the stage where there is common curriculum for all children. Its purpose is to build a strong foundation in the fundamental principles of all basic subjects. At the end of this stage, after public examination a student joins senior secondary education either in vocational or academic streams preparing him/her self for different walks of life.

The higher education structure encompasses programs ranging from three years of general education in arts, sciences, and commerce as a part of $10+2+3$ structure to five to six years of other professional courses to secure the first degree. Second and terminal degree programs also take two and three years respectively depending on the type of disciple the student attends.

\section{Teaching and Teachers in India}

It is commonly recognized that teachers have a crucial role in the development of effective education system. Availability of professional, trained and above all highly motivated teachers is an important aspect in ensuring meaningful access and success to education (Lewin 2007).

There are policy initiatives in India that envisage the important role of teachers. They also recommend cautious recruitment since teachers shape generations from the grass root level to the highest phase. For example, The National Policy on Education (1986) emphasised that: "The method of recruitment of teachers would be reorganised to ensure objectivity, merit and conformity with spatial and functional requirements". Moreover, The National Commission on Teachers (1983-85) observed: "To recruit teachers more scientifically, the desirable competencies of teachers should be listed on the basis of practical and applied research". It is proclaimed that high proficiency in the subject area, good linguistic ability, efficiency in communication skills and passion for children are some of the desirable qualities of a good teacher (Arora, 2002:93). A task force was also constituted by the National Council for Teacher Education (NCTE) in 1999 to evolve eligibility criteria for the recruitment of teachers. The council issued a notification relating to teachers' qualifications despite their recruitment and retention is still challenging.

As a result, currently, for most students in India, the learning environment is pretty abysmal. School consists of a one-room schoolhouse, one teacher covering multiple grades, teacher-student ratio is not at standard which exacerbate high levels of teacher absence and low levels of teaching activity. It should be noted as well that many rural public schools barely have the most basic facilities (a closed-in building, drinking water, toilets, desks, a blackboard). In addition to these challenges, many rural schools are seriously understaffed, especially in the larger states of Uttar Pradesh and Bihar. This might be related with motivation. There is no system in place to motivate teachers to improve academic achievement, and very little training available to strengthen teaching practices. For instance, though the 1986 National Policy on Education upgraded the standard curriculum with increased requirements in English and in the sciences, the curricular changes were not linked with new ways of engaging pedagogies and assessing student progress.

In conclusion, without efforts to recruit large numbers of criteria based new teachers and an investment of resources to upgrade school facilities, India will be hard-pressed to scale up elementary education and improve instructional outcomes for its upcoming generation.

\section{Governance and Financing}

When India became independent in1947, Department of Education was established within the Ministry of Human Resource Development. It coordinates planning with the States, provides funding for experimental programs, and acts through the University Grants Commission and the National Council of Educational Research and Training (NCERT) to develop standards, instructional materials, and design textbooks. The NCERT's textbooks serve as models since States are not legally enforced to use the national syllabus.

Accordingly, the central government drafts five-year plans that address education policy and funding issues for education. State-level ministries of education coordinate education programs at the regional levels. Administration of urban government schools are supervised by both the state education ministry and the municipal government. In rural areas, either the district board or the panchayat (village council) has oversight on school functioning, which often brings heightened politicization to the teacher appointment process (Talik,1990;Azad,2005;Chandra,2006). 
The State governments provide most of educational funding either directly to run schools or support privatelyrun schools through grants. However, a phenomenon of growing importance over recent years has been the mushrooming of schools in each state that are completely independent of government funding; these are called private, unaided schools. These schools typically pay much lower salaries than government schools, and are therefore able to hire more teachers, reduce multi-grade teaching, and have smaller classes. They are also able to exercise more oversight on teachers and have higher rates of teaching activity (Mehta, 2010).

Regarding the financing of education, on the recommendation of the Education Commission (1966), the Indian government (1968) set a goal of spending six percent of GNP in education by 1986, but this has never been achieved. In the early $1950 \mathrm{~s}$, it was as low as 1.2 percent, it has moved up gradually to around 4 percent of GNP (4.2 in 2000/01). Human Development Report (2001) revealed that, India ranked $104^{\text {th }}$ among the 143 countries listed, with respect to the share of GNP spent on education. A recent UNESCO study also indicates countries spending much less than India are getting better results.

Belatedly cognizant of the importance of primary education, the government has in recent years shifted the focus of its funding to primary and middle grades in an attempt to boost overall literacy levels. Higher education funding in general has seen a decline over the last two decades, although the world-renowned "institutions of national importance" in technology and management have not suffered budget deficit (Seshadri, 2002).

The central government allocation of resources to education is relatively small compared to the state budgets (10 percent of total spending on education). The major problem, apart from the scarcity of resources, there are no credible reports on the distribution of government resources resulted in difficulty of tracking how much of the allocations actually reach the school system for which they have been budgeted. Undoubtedly, the Department of Education receives the majority of expenditure, but funds are also released to a number of centrallysponsored projects and programs, making it indistinguishable how much reaches the district and school level. Moreover, teacher salaries take $80 \%$ of the total budget leaving very little for key investments in infrastructure, teacher training, instructional materials, and other aspects of quality management strategies. India's investment in education ,in general, can be deduced as inadequate in terms of efficiency and equity, yet the country's prized professional higher education institutes continue to be well-funded to produce high quality graduates (NCEE,2005). The year-wise achievements of physical and financial targets of the scheme during the last five years for elementary education are given below (NCEE, 2005):-

\begin{tabular}{|llllll|}
\hline Components & $2009-10$ & $2010-11$ & $2011-12$ & $2012-13$ & $2013-14$ \\
\hline Children covered (in Cr.) & 11.36 & 10.46 & 10.54 & 10.68 & 10.80 \\
\hline $\begin{array}{l}\text { Food grains allocated } \\
\text { (in lakh MTs) }\end{array}$ & 27.71 & 29.40 & 29.09 & 29.55 & 29.77 \\
\hline Budget allocation (in Cr.) & 7359.15 & 9440 & 10380 & 11937 & 13215 \\
\hline Total Exp. (in Cr.) & 6937.79 & 9128.44 & 9901.91 & 10868 & 10927.21 \\
\hline
\end{tabular}

Table 2: coverage and expenditure trends

\section{DISCUSSION AND CONCLUSION}

The education system of the two countries, as presented in the carefully selected issues, has common elements and differences. The beginning of education is as old as the history of the nation and might be named as ancient education. In Ethiopian context, for example, beginning of ancient education is related with two aspects; indigenous and religion. Even if these two perspectives are sometimes overlapping, it is possible to describe taking in to account their unique features. Since human beings began communal life, there has been the intention of transferring knowledge, skills and values orally (in most cases) through certain strategies to maintain and develop what has been done by their ancestors. Indigenous education is an integral, valuable and inseparable part of indigenous people's lives that has helped them to survive for centuries. We think this works for India too where the guru's of the day enjoyed shaping generations using the wisdom of the then society. History tells us a lot the role indigenous education played and is playing in the education system of the country.

Religion also has pivotal place in the education system of the two nations. Before the introduction of major religions from the Middle East, indigenous beliefs (though in most cases didn't have inscriptions) were the lifeblood of citizens in all aspects of human endeavour. Later, when the alien religions introduced, they began to have written form which resulted in basic education (how to read and write). Gradually they established firm base for modern/western education. If we take the case of Ethiopia for instance, imported religions, mainly Christian and Islam contributed a lot for the then civilization of the country and laid foundation for the contemporary education of the west. 
The other cardinal issues of the education system are national education policy and the structure of the system. As it may be noticed from the presentations, the current education policy is the result of long time concerted efforts of the previous governments. In its present sense, it is aimed at serving the needs of the citizens. It tries to address all diversity irrespective of gender, religion, socio-economic background; etc. It is promulgated as the right of every citizen especially at primary levels. The typical problem, however, is the problem of implementation. It seems, there is no strong commitment, from all stakeholders, and tool to put in to effect every strategies designed in line with the national policy. This might depend on the capacity of the regions or states for they have different human and material resources. For example, the northern and southern states of India have quite different status of education. This is true in Ethiopia as well where the regions in the eastern and western peripheries lag behind others.

The pattern of education is similar except the first cycle primary level for Ethiopia ends at grade four which is grade five in the Indian case. The structure has two levels of primary education, then lower secondary education (grades 9 and 10) followed by preparatory stages (grades11 and 12) before joining higher learning institutions. The curriculum is also designed in line with the nature of the discipline and the developmental stages of the learners ranging from environmental sciences at primary level to hard sciences in the other extreme. There are also options for learners to join the world of work at various levels especially through vocational and technical education based on their interest and merit.

Teacher and teaching in both countries given less emphasis in practice though the policy documents recognize as the most important profession to propel forward the status of the nation. The major reasons identified for lower status of teaching are said to be students with low achievement level join the profession, they don't have motivation, the working condition is not attractive, and the recruitment and training is politicized in most cases. Because of these and other related factors, the professional contribution they are making is not worth mentioning.

Regarding governance and financing, since the state formation of the two countries is federalism, decentralization of the power to the states or regions is one major feature. Accordingly, the central government takes the lions share in shaping and formulation of the overall education system through national education policy collecting and organizing all important educational issues from the grass root level. Regions are in charge of management of the local issues. They are expected to develop curriculum and select teaching strategies taking the priorities of the society at most. However, there are instances when the central government acts as unitary power especially in recruitment and assignment of educational experts not only based on merit but also political commitment. The flow of resources to the target localities has its own limitations. For one thing, it is not sufficient to improve the standard of education. On the other hand, the allotted resource itself doesn't reach the target group mainly because of administrative loopholes.

As a conclusion, the point to be noted is that a comparative perspective cannot provide us exhaustively plans of action unless accompanied by broad horizons. In the era of globalization, thinking only in ones boundaries costs a lot. A comparative analysis of this sort is an opportunity to see things beyond one's own perspectives to work on the deficiencies without overlooking the merits. From both countries perspective, we have to recognize that students are at the centre stage to foster innovation and creativity. We have to take steps to move ahead towards a desired vision if we have to have any impact on the global front. This will imply a policy framework having a combination of increasing access, equity and quality together with the right mixture of autonomy and regulation for far-reaching missions to be accomplished.

\section{References}

[1] Adane, T. (1996). A Historical Survey of State Education in Ethiopia. Addis Ababa: Asmara.

[2] Alao,O.(2013, September 21). Education and Building a culture of Peace. Retrieved from http://www.upf.org/resources/speeches-and-articles/5503-o-alao-educating-and-building-a-culture-of-peace

[3] Amare Asgedom et al., (2006) Ethiopia Pilot Study of Teacher Professional Development Quality in Education, Teaching, and Learning: Perceptions and Practice. Institute of Educational Research, Addis Ababa University: Addis Ababa

[4] Arora, G. L. (2002) Teachers and their Teaching Need for New Perspectives, Ravi Books, Delhi.

[5] Azad J. L. (2005). Financing of Higher Education in India with special Reference to resource Mobilisation. University News, 42(52), pp. 97-102, December 27, 2004-January 02, 2005, AIU, New Delhi.

[6] Bereday, G. (1964). Comparative method in education. New York: Holt, Rinehart and Winston.

[7] Chanda, R. (Eds.) (2006). Trade in services and India: Prospects and Strategies. New Delhi, Wiley India.

[8] Clark N. (2006), Education in India, WES - World Education News \& Reviews (WENR), New York.

[9] Claire Sc. (2013). Ethiopia: The African tiger. Deutsche Bank AG, DB Research, D-60262 Frankfurt am Main, Germany 
[10] Herbst, J.(2000). States and Power in Africa: Comparative Lessons in Authority and Control. Princeton: Princeton University Press.

[11] Lewin, K. (2007). Improving Access, Equity and Transitions in Education: Creating a Research Agenda CREATE Pathway to Access Research Monograph No. 1 Brighton University of Sussex.

[12] Manzon, M. (2007). Comparing places. In M.Bray, B. Adamson, \& M. Mason (Eds.), Comparative education research approaches and methods (pp. 85-121). Hong Kong : Springer

[13] Mehta, A.C. (2010) Elementary Education in India-Progress towards UEE, NUEPA, New Delhi.

[14] Ministry of Education. (2014). Education Statistics Annual Abstract, Addis Ababa.

[15] Ministry of Education.(1998). Ethiopia Education Sector Development Programme (1997/8 - 2001/2). Addis Ababa, Ministry of Education.

[16] MoE. (2002). Education and Training Policy and Its Implementation. Addis Ababa: Ministry of Education.

[17] NCERT (2005) National Curriculum Framework for Teacher Education, National Council for Teacher Education, New-Delhi.

[18] Pankhurst, R. (1976). "Historical background of education in Ethiopia." In M.L Bender,J.D.

[19] Persis,K.(2015).The Emerging Indian Economy. A report of The CSIS Wadhwani Chair in US. India Policy Studies. Center for Strategic and International Studies.

[20] Ranganathan, S.(2007), Educational Reform and Planning Challenge, Kanishka Publishers, Distributors, New Delhi

[21] Rockoff, J.E. (2004). "The impact of individual teachers on student achievement: Evidence from panel data. American Economic Review 94 (2), 247-252.

[22] Serbessa , D. D. (2006). Tension between traditional and modern teaching approaches in Ethiopian primary schools. CICE Hiroshima University, Journal of International Cooperation in Education, 9 (1), 123-140

[23] Seshadri, C. (2002) Educating the Educators, Review of Primary Teacher Training in R.Govinda (ed.) India Education Report-A Profile of Basic Education, Oxford University Press, New-Delhi, 2002.

[24] Tekeste, N. (1990) The Crisis of Ethiopian Education: Some Implications for Nation Building, Uppsala Reports on Education 29, Department of Education, Uppsala University.

[25] Teshome G.(1979). The Conflict of Ethnic Identity and the Language of Education Policy in Contemporary Ethiopia. Michigan University.

[26] Tilak,J.B.G .(1990c)Trends in Public and Private Finances for Education in India. World Bank International Conference on Education Finance, Beijing, China.

[27] TGE. (1994). Education and Training Policy. EEP 86, Addis Ababa April 1994, 33pp.

[28] UNECA (2011).Economic Report on Africa. Governing development in Africa - the role of the state in economic transformation. Addis Ababa. Ethiopia.

[29] Workneh A. \& Tassew W, (2013). Teacher Training and Development in Ethiopia: Improving Education Quality by Developing Teacher Skills, Attitudes and Work Condition Young Lives in October 2013.

[30] Zewdie, M. (2000). A Study Guide for Curriculum Implementation and Evaluation, Unpublished Teaching Materials for the Course Educ.676, Addis Ababa University. 